\title{
Protein and siRNA delivery by transportan and transportan 10 into colorectal cancer cell lines
}

\author{
Piotr M. Wierzbicki ${ }^{1}$, Marzena Kogut-Wierzbicka ${ }^{1}$, Jaroslaw Ruczynski ${ }^{2}$, \\ Kamila Siedlecka-Kroplewska ${ }^{1}$, Lucyna Kaszubowska ${ }^{1}$, Agnieszka Rybarczyk ${ }^{1}$, \\ Magdalena Alenowicz ${ }^{2}$, Piotr Rekowski² ${ }^{2}$ Zbigniew Kmiec ${ }^{1}$
}

${ }^{1}$ Department of Histology, Medical University of Gdansk, Gdansk, Poland

${ }^{2}$ Faculty of Chemistry, University of Gdansk, Gdansk, Poland

\begin{abstract}
Introduction. Cell penetrating peptides (CPPs) have the ability to translocate through cell membranes with high efficiency and therefore can introduce biological agents with pharmaceutical properties into the cell. Transportan (TP) and its shorter analog transportan 10 (TP10) are among the best studied CPPs, however, their effects on viability of and cargo introduction into colorectal cancer (CRC) cells have yet not been investigated. The aim of our study was to evaluate the cytotoxic effects of TP and TP10 on representative CRC lines and the efficiency of protein (streptavidin) and siRNA cargo delivery by TP-biotinylated derivatives (TP-biot).

Material and methods. HT29 (early stage CRC model) and HCT116 (metastatic CRC model) cell lines were incubated with TP, TP10, TP-biot1, TP-biot13 and TP10-biot1. The effects of studied CPPs on cell viability and cell cycle were assessed by MTT and annexin V assays. The uptake of streptavidin-FITC complex into cells was determined by flow cytometry and fluorescence microscopy, with the inhibition of cellular vesicle trafficking by brefeldin A. The efficiency of siRNA for SASH1 gene delivery was measured by quantitative PCR (qPCR). Results. Since up to $10 \mu \mathrm{M}$ concentrations of each CPP showed no significant cytotoxic effect, the concentrations of $0.5-5 \mu \mathrm{M}$ were used for further analyses. Within this concentration range none of the studied CPPs affected cell viability and cell cycle. The efficient and endocytosis-independent introduction of streptavidin-FITC complex into cells was observed for TP10-biot1 and TP-biot1 with the cytoplasmic location of the fluorescent cargo; decreased SASH1 mRNA level was noticed with the use of siRNA and analyzed CPPs.

Conclusions. We conclude that TP, TP10 and their biotinylated derivatives can be used as efficient delivery vehicles of small and large cargoes into CRC cells. (Folia Histochemica et Cytobiologica 2014, Vol. 52, No. 4, 270-280)
\end{abstract}

Key words: CPP; transportan; TP10; HT29; HCT116; SASH1; siRNA; cell cycle; apoptosis

\section{Introduction}

Cell-penetrating peptides (CPPs), also known as peptide transduction domains (PTDs), make a new class of transmembrane delivery vectors with high pharmaceutical potential [1]. CPPs can be taken up

Correspondence address: P.M. Wierzbicki, Ph.D.

Department of Histology

Medical University of Gdansk

Debinki St. 1, 80-210 Gdansk

tel.: +48 5834914 37, fax: +48583491419

e-mail: pwierzb@gumed.edu.pl by living cells and can deliver different covalently coupled cargoes into cells both in vitro [2] or in vivo [3, 4]. Among transport peptides penetratin [5], Tat-peptide [6], oligoarginine [7], and transportan (TP) [8] belong to the best characterized.

TP is a 27 amino acids (aa) long chimeric peptide (Table 1) containing 12 aa from the amino-terminal part of the neuropeptide galanin and the 14 aa long mastoparan (Vespula lewisii wasp venom), connected via a lysine residue [8]. TP reveals some characteristic features of both galanin and mastoparan since it inhibits the binding of galanin to GALR-1 receptor as well as modulates the activity of Gs proteins due 
Table 1. Amino acid sequences of cell-penetrating peptides used in the study

\begin{tabular}{|l|l|c|}
\hline CPP abbreviation & Sequence & Length [aa] \\
\hline TP & GWTLNSAGYLLGKINLKALAALAKKIL-amide & 27 \\
\hline TP-biot1 & biotin-GWTLNSAGYLLGKINLKALAALAKKIL-amide & 27 \\
\hline TP-biot13 & GWTLNSAGYLLGK(biotin)INLKALAALAKKIL-amide & 27 \\
\hline TP10 & AGYLLGKINLKALAALAKKIL-amide & 21 \\
\hline TP10-biot1 & biotin-AGYLLGKINLKALAALAKKIL-amide & 21 \\
\hline
\end{tabular}

to the inhibition of GTPase activity [9]. The shorter analogs of TP (TP7-15) showed lower cytotoxity in comparison to TP, galanin and mastoparan [8]. TP10, a 21 aa version of TP (Table 1) has been widely studied due to its high cellular uptake rate and lack of the inhibition of GTPase activity [10].

Although the uptake of different cargoes and cytotoxicity of many CPPs has been analyzed in various types of cell cultures, the effects of TP and TP10 on colorectal cancer (CRC) cell lines have yet not been investigated. Therefore, the main goal of the present study was to analyze the effects of TP and TP10 and their derivatives on the viability and cell cycle of HT29 and HCT116 cell lines, which are related to early (HT29) and metastatic (HCT116) stages of CRC.

Currently, there is no consensus on how transpor$\tan$ and its derivatives deliver molecules to the cell. Various mechanisms such as different types of endocytosis as well as direct translocation via the plasma membrane have been proposed [11,12]. The mode of internalization can depend on peptide concentration, size of the cargo molecule, temperature and specific properties of the plasma membranes of the studied cells [13]. The translocation can take place via the energy dependent or independent route and multiple factors have been suggested to control the balance between various internalization pathways [14-16]. Similarly, some reports suggest direct translocation to the cell of TP10 [17, 18], whereas other studies suggest its endocytosis $[12,19]$. Thus, we aimed to check possible method of TP and TP10 penetration into CRC cells by determining their transport ratios after inhibition of endocytosis with the use of brefeldin A [20-22]. Additionally, we used a model of cellular penetration based on an introduction of a large, FITC-labeled protein (streptavidin, M.W. $=52.8 \mathrm{kDa} v s .2 .1$ or $2.8 \mathrm{kDa}$ for TP10 and TP molecules, respectively) or small siRNA molecule which decreases mRNA ratio of SASH1 gene. Our investigation of TP and TP10 penetration into CRC cell lines may contribute to the results of other studies on CPP attached to peptides [23], short interfering RNA (siRNA) and DNA oligonucleotides [24] as well as peptide nucleic acid (PNA) oligomers [25].

\section{Material and methods}

All plastic labware was obtained from Sarstedt (Nümbrecht, Germany) and the culture reagents were obtained from SigmaAldrich (St. Louis, MO, USA), if not stated otherwise.

Cell lines. Human colorectal cancer cell lines HT29 (ATCC cat. \# HTB-38) and HCT116 (ATCC cat. \# CCL-247) were cultured at a density of $1-2 \times 10^{6}$ cells per $25-\mathrm{cm}^{2}$ flask in McCoy (HT29) or Dulbecco's Modified Eagle's (DMEM) medium (HCT116), supplemented with $10 \%$ fetal bovine serum (FBS) and penicillin $(100 \mathrm{U} / \mathrm{mL}) /$ streptomycin $(100 \mu \mathrm{g} / \mathrm{mL})$. Cultures were conducted at $37^{\circ} \mathrm{C}$ in humidified atmosphere containing $5 \% \mathrm{CO}_{2}$. The cells were detached every $2-3$ days with $0.25 \%$ trypsin/EDTA. The medium was exchanged after each passage. Cells were cultured for $24 \mathrm{~h}$ before initiation of the experiments.

Peptide and siRNA synthesis, purification and handling. All peptides used in this study (Table 1) were synthesized in the Department of Chemistry of Biological Active Molecules, University of Gdansk, Poland, using the Fmoc strategy of solid-phase peptide synthesis as described previously [26]. Purification and analysis of the peptides were performed with the use of MALDI-TOF mass spectrometer. All peptides were lyophilized and stored at $-30^{\circ} \mathrm{C}$ until use. Peptide solutions at dedicated concentrations were prepared directly before use in plastic vials by the addition of $0.9 \% \mathrm{NaCl}$.

Lyophilized siRNA for SASH1 gene (Abcam, Cambridge, UK) was dissolved to $10 \mu \mathrm{M}$ stock in nuclease-free water (A\&A Biotechnology, Gdynia, Poland). The vials were stored at $-80^{\circ} \mathrm{C}$ until further use.

Assessment of CPP cytotoxicity. The MTT assay, a colorimetric method for measuring the activity of mitochondrial succinate dehydrogenase in living cells, was used for the cytotoxicity assessment according to previously described procedure [27] with some modifications [28]. In brief, HT29 or HCT116 cells were seeded in 96-well plates to a density of 10000 cells/well in $0.2 \mathrm{~mL}$ of above-specified culture media. After $24 \mathrm{~h}$ following concentrations $[\mu \mathrm{M}]$ of CPPs were added to wells: 0.05, 0.1, $0.5,1,5,10,25,50$. As a negative control cells were treated with $0.9 \% \mathrm{NaCl}$. After $2 \mathrm{~h}$ of incubation $\left(5 \% \mathrm{CO}_{2}, 37^{\circ} \mathrm{C}\right), 15 \mu \mathrm{L}$ MTT solution was added into each well to reach the final con- 
centration of $10 \mathrm{mg} / \mathrm{mL}$. After further incubation for $2 \mathrm{~h}(5 \%$ $\mathrm{CO}_{2}, 37^{\circ} \mathrm{C}$ ) the cells were centrifuged at $20817 \mathrm{~g}$ for $3 \mathrm{~min}$ at $4^{\circ} \mathrm{C}$ and the medium was removed. Formazan crystals present in mitochondria of metabolically active cells were solubilized with $100 \mu \mathrm{L}$ of dimethylsulfoxide (DMSO), and the dye concentration was measured using the EL $\times 800$ Microplate Reader (BioTek, Highland Park, IL, USA) at $570 \mathrm{~nm}$ wavelength.

Cell cycle analysis. Propidium iodide (PI) DNA incorporation was used to evaluate DNA content in HT29 and HCT116 cells. Briefly, $3 \times 10^{5}$ cells were seeded in a 6 -well plate and incubated $\left(5 \% \mathrm{CO}_{2}, 37^{\circ} \mathrm{C}\right)$ in above-specified culture media for $24 \mathrm{~h}$. After medium exchange, cells were incubated with analyzed CPPs at $0.1 \mu \mathrm{M}$ or $5 \mu \mathrm{M}$ final concentrations for $24 \mathrm{~h}\left(5 \% \mathrm{CO}_{2}, 37^{\circ} \mathrm{C}\right)$. As a negative control $0.9 \% \mathrm{NaCl}$ was used. After incubation, cells were harvested with trypsin, washed twice with cold phosphate-buffered saline (PBS, each time the centrifugation conditions were $400 \mathrm{~g}$ for $5 \mathrm{~min}$ at room temperature). Then cells were fixed gently by adding $75 \% \mathrm{EtOH}$ and placing at $-20^{\circ} \mathrm{C}$. After $24 \mathrm{~h}, \mathrm{EtOH}$ was removed by centrifugation in $400 \mathrm{~g}$ for $5 \mathrm{~min}$ at room temperature and cell pellet was washed with cold PBS $\left(400 \mathrm{~g} ; 10 \mathrm{~min} ; 4^{\circ} \mathrm{C}\right)$ and resuspended in $450 \mu \mathrm{L}$ of PI buffer (50 $\mu \mathrm{g} / \mathrm{mL}$ PI, $25 \mu \mathrm{g} / \mathrm{mL}$ RNase, PBS, Molecular Probes-Life Technologies, Carlsbad, CA, USA). After $30 \mathrm{~min}$ incubation at $37^{\circ} \mathrm{C}$ in darkness, stained cells were analyzed with the use of FACScan flow cytometer (BD Biosciences, San Jose, CA, USA) in the Department of Pathophysiology, Medical University of Gdansk, Poland (courtesy of Professor J. Witkowski). WinMDI 2.9 free software was used for data analysis.

Apoptosis assay. Analysis was based on changes of phosphatidylserine localization within cell membrane using Annexin-V FITC Apoptosis Detection Kit I (BD Pharmingen, San Diego, CA, USA) according to the manufacturer's instructions. Briefly, $3 \times 10^{5}$ cells cultured in 6-well plates for $24 \mathrm{~h}(5 \%$ $\mathrm{CO}_{2}, 37^{\circ} \mathrm{C}$ ); next they were treated with analyzed CPPs to a final concentration of $5 \mu \mathrm{M}$. After 24 or $48 \mathrm{~h}$ supernatant was removed, cells were trypsinized and washed twice with PBS and incubated with $5 \mu \mathrm{L}$ of FITC-conjugated annexin V $(\mathrm{anV})$ and $\mathrm{PI}$ for $15 \mathrm{~min}$ at room temperature. After addition of $0.4 \mathrm{~mL}$ Buffer A (BD Pharmigen), cells were analyzed by flow cytometry. The obtained fluorescent results were divided into four groups, depending of the signal: anV (-), PI (-) - living cells; anV (+), PI (-) — early apoptosis; anV (+), PI (+) — late apoptosis; anV (-), PI (+) — cellular debris (further omitted in final calculation).

Protein cargo delivery with the use of biotinylated derivatives of TP and TP10. Streptavidin conjugated with FITC (strept-FITC) was used as a cargo molecule in this experiment. Biotinylated CPPs (Table 1) were used in this study since the biotin-steptavidin bonds are known as one of the strongest between biologically active molecules $\left(\mathrm{Kd} \approx 10^{-14} \mathrm{~mol} / \mathrm{L}\right)$ [29]. The streptFITC-CPP complexes were obtained by the incubation of $50 \mu \mathrm{L}$ of TP-biot1, TP-biot13 or TP10-biot1 (all at $20 \mu \mathrm{M}$ concentra- tion) with $50 \mu \mathrm{L}$ of $5 \mu \mathrm{M}$ strept-FITC in the above-specified serum-free media, for $30 \mathrm{~min}$ at $25^{\circ} \mathrm{C}$. Cells cultures at the density of $3 \times 10^{5}$, on 6 -well plate were treated for $2 \mathrm{~h}$ at $25^{\circ} \mathrm{C}$ with strept-FITC-CPP complex to a final concentrations of $0.5 / 2 \mu \mathrm{M}$ strept-FITC/CPP or 1.0/4.0 $\mu \mathrm{M}$ strept-FITC/CPP. Thereafter, cells were washed with PBS, trypsinized, washed twice with PBS and the cell culture serum-free media were added. The transport of streptavidin-FITC into cells was also assessed with the use of non-biotinylated TP and TP10 at the concentration of $0.25 \mu \mathrm{M}$ strept-FITC/CPP complex. The following controls were prepared: negative — cells with $0.9 \% \mathrm{NaCl}$ added; CPP without FITC - cells incubated with TP-biot1, TP-biot13 or TP10-biot1 at a final concentration of 2 or $4 \mu \mathrm{M}$; strept - cells incubated only with strept-FITC at a final concentration $0.5 \mu \mathrm{M}$ or $1 \mu \mathrm{M}$. Samples were divided into two vials and first set was analyzed by flow cytometry to quantify the FITC signal. The second set of samples was placed on microscopic glass slides and immediately observed by fluorescence microscopy (Nikon Eclipse 800 microscope, Nikon, Tokyo, Japan). The images were acquired with Hamamatsu camera (model no. C47-42-95) at $494 \mathrm{~nm}$ wavelength and archived.

Inhibition of endocytosis by brefeldin A. To check if incorporation of strept-FITC-CPP complex into the cells occurred by endocytosis, the cellular vesicular traffic was inhibited with the use of brefeldin A [30]. Briefly, cells were incubated for $1 \mathrm{~h}$ $\left(5 \% \mathrm{CO}_{2}, 37^{\circ} \mathrm{C}\right)$ in serum-free cell media containing $10 \mu \mathrm{g} / \mathrm{mL}$ brefeldin A. Thereafter, cells were washed with PBS, trypsinized, washed twice with PBS and the cell culture serum-free media were added. Then cells were processed to measure the transport of the strept-FITC-CPP complexes by flow cytometry as described above for streptavidin delivery protocol.

siRNA cargo delivery. $S A S H 1$ gene has been chosen as a target for siRNA delivery by using TP or TP10, since our preliminary data showed a stable expression of this gene in HT29 and HCT116 cells. We used a procedure described by Ezzat et al. [31]. Cells were seeded into 24-well plates at a density of 50000 cells/well in $1 \mathrm{~mL}$ of medium. After $24 \mathrm{~h}$ incubation at $37^{\circ} \mathrm{C}$, siRNA was added into each well at the concentrations of 10 or $50 \mathrm{nM}$. CPPs (TP, TP-biot1, TP10 and TP10-biot1) were added to a final concentration of $2 \mu \mathrm{M}$ to each well containing cells and siRNA. All assays were run in triplicate. The cells were then incubated $\left(5 \% \mathrm{CO}_{2}, 37^{\circ} \mathrm{C}\right)$ for 12,24 and $48 \mathrm{~h}$. After incubation, cell pellet was obtained by centrifugation at $20817 \mathrm{~g}$ for $5 \mathrm{~min}$ at $4^{\circ} \mathrm{C}$, and the cells were stored at $-80^{\circ} \mathrm{C}$. mRNA was extracted with the use of modified Chomczynski-Sacchi phenol-chloroform method (Total RNA Mini kit, A\&A Biotechnology, Gdynia, Poland) and eluted with $70 \mu \mathrm{L}$ of RNAse-free water, followed by RNA purity and concentration measurement (NanoDrop ND1000, Thermo Fisher Scientific, Fitchburg, WI, USA). $1 \mu \mathrm{g}$ of total RNA was reversibly transcribed (RevertAid kit, Fermentas-Thermo Fischer Scientific) at $42^{\circ} \mathrm{C}$ for $60 \mathrm{~min}$, The resulting cDNA was quantified by qPCR (StepOnePlus, Life Technologies-Applied Biosystems, 
Grand Island, NY, USA). The primers' sequences for GAPDH (reference gene [32]) are: 5'-CTGTTCGACAGTCAGCCGCATC and 5'-GCGCCCAATACGACCAAATCCG, and for SASH1 gene: 5'-GATACGCAGAGGACTTGGATCAGC and 5'-ATGGGCAGACCGATGGAAATGAG. The qPCR reactions were carried out in triplicate in $10 \mu \mathrm{L}$ sample which contained $1 \mu \mathrm{L}$ of four-times diluted cDNA and SybrGreen No ROX kit (BioLine, London, UK) using the following protocol: $2 \mathrm{~min}$ at $95^{\circ} \mathrm{C} ; 40$ cycles of $\left(5 \mathrm{~s}\right.$ at $95^{\circ} \mathrm{C}, 10 \mathrm{~s}$ at $59^{\circ} \mathrm{C}, 15 \mathrm{~s}$ at $72^{\circ} \mathrm{C}, 10 \mathrm{~s}$ at $77^{\circ} \mathrm{C}$ - fluorescence read). Dynamic melt curve analyses from $60^{\circ} \mathrm{C}$ to $95^{\circ} \mathrm{C}$ were conducted. Negative control containing water instead of cDNA as well as positive control with cDNA from untreated cells were added to each run. Data were archived using StepOne Software ver. 2.2 (Life Technologies-Applied Biosystems).

Statistical analysis. Statistica 10 software (StatSoft, Tulsa, OK, USA) was used for statistical analysis. Data represent mean values \pm standard deviation (SD). Since partial values did not pass D'Agostino normality test, we used non-parametric Mann-Whithey U test and Kruskal-Wallis ANOVA. Microsoft Excel 2013 (Microsoft Corp., Redmond, WA, USA), GraphPad Prism 6 (GraphPad Software Inc., La Jolla, CA, USA) were used for the generation of plots. $\mathrm{P}<0.05\left(^{*}\right)$ and $\mathrm{p}<0.01\left({ }^{* *}\right)$ were considered as statistically significant.

\section{Results}

\section{Cytotoxic effects of TP, TP10 and their biotinylated derivatives on HT29 and HCT116 cells}

The viability of HT29 and HCT116 cells incubated with various concentrations of TP, TP10, TP10-biot1, TP-biot1 and TP-biot13 was assessed by the MTT assay (Figure 1). Since 5 to $10 \mu \mathrm{M}$ concentration range of any CPP did not substantially affect viability of CRC cells (Figure 1), hence CPPs in a concentration range of $0.1-5 \mu \mathrm{M}$ were used in further experiments. The $10 \mu \mathrm{M}$ concentration of TP, TP10 and their biotinylated derivatives can be treated as a common cytotoxic border for the analyzed CRC cell lines.

Based on viability-regression curves, we also calculated CPP lethal doses (LD) sufficient to kill 50 or 90\% CPP-treated cells (LD50, LD90, Table 2). Similar sensitivity to the studied CPPs were observed in both cell lines after $24 \mathrm{~h}$ incubation. Slightly higher cytotoxicity was observed for TP and TP10 biotinylated at position 1 (TP-biot1, TP10-biot1, Table 2). The least cytotoxic CPP in both analyzed cell lines was TP-biot13 which hardly affected cell viability; LD90 value was calculated far beyond applied TP-biot13 concentrations (Figure 1C, Table 2).

\section{Influence of CPPs on cell cycle progression and induction of apoptosis}

HT29 and HCT116 cells were incubated for $24 \mathrm{~h}$ with CPPs at 0.1 and $5 \mu \mathrm{M}$ concentrations and the possible alterations of cell distribution in different cell cycle phases in comparison to untreated (control) cells were analyzed by flow cytometry. No significant changes in cell cycle phases were observe in HT29 and HCT116 cells incubated for $24 \mathrm{~h}$ with CPPs at 0.1 and $5 \mu \mathrm{M}$ concentrations (data not shown). Some delicate alterations concerning the percentage of apoptotic cells were, however, observed in HCT116 cells (Figure 2C, D). Cells of both lines treated for $24 \mathrm{~h}$ with TP10-biot1 and TP-biot1 revealed slightly reduced percentage of living cells and increased percentage of early or late apoptotic cells compared to control ones. To check if prolonged incubation with the highest used concentration of CPPs $(5 \mu \mathrm{M})$ can induce apoptosis of CRC cells we incubated the cells for up to $48 \mathrm{~h}$ (Figure 2B, D). Although in both HT29 and HCT116 cells cell viability decreased and the percentage of early and late apoptotic cells increased, these changes were not significant. The only significant decrease in the viability of HT29 and HCT116 compared to control cells was observed in cells incubated for $48 \mathrm{~h}$ with TP10-biot1 (Figure 2B, D).

\section{Delivery of FITC-labeled streptavidin into cells by biotinylated TP and TP10}

Delivery of strept-FITC was performed to check if large protein cargo can be introduced into cells with the use of TP-biot1, TP-biot13 and TP10-biot1 (Figure 3). Since one streptavidin molecule binds four biotin molecules [29], for quantitative analysis two different concentrations of biotinylated CPPs were used: 2 and $4 \mu \mathrm{M}$ which corresponded to 0.5 and $1 \mu \mathrm{M}$ streptavidin concentration.

The efficient delivery of strept-FITC into HCT116 cells with the use of studied biotinylated derivatives was observed after $2 \mathrm{~h}$ of incubation with $4 \mu \mathrm{M} \mathrm{CPP}$ (Figure 3B). The significant increase of fluorescent signal was observed for TPbiot 1 at $4 \mu \mathrm{M} \mathrm{CPP}$ concentration. In relation to control cells the fluorescence signals in HT29 were 7 times higher, while in HCT116 were 4 times higher. For TP10-biot1 comparable efficiency of delivery rate at $4 \mu \mathrm{M}$ concentration was observed only in HCT116 cells but not in HT29 cells (Figure 3B).

On the contrary, TP-biot13 was found to be ineffective in delivery of CPPs, since no successful delivery at $2 \mu \mathrm{M}$ CPP into HCT116 cells could be observed. The 
$\mathbf{A}$

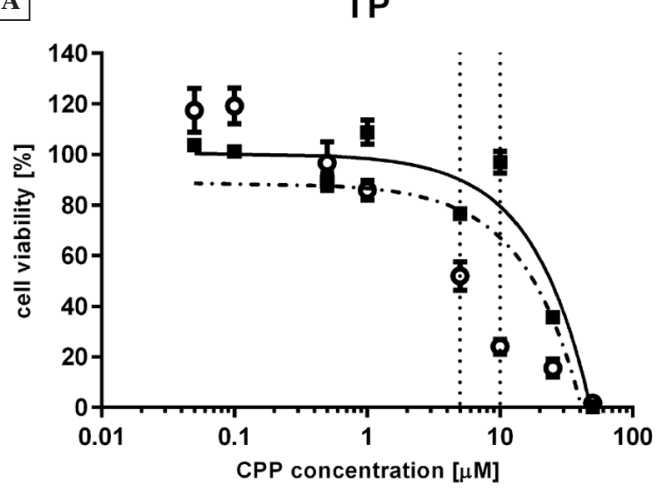

C

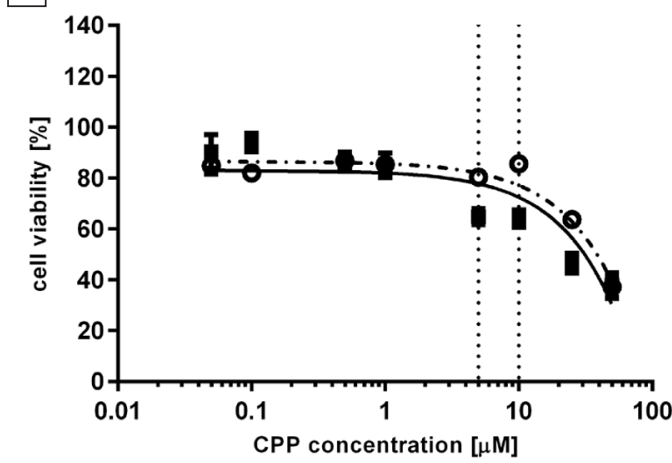

E

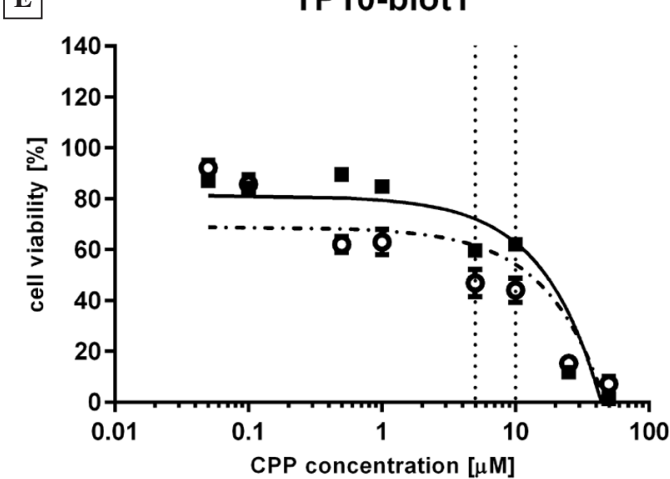

B

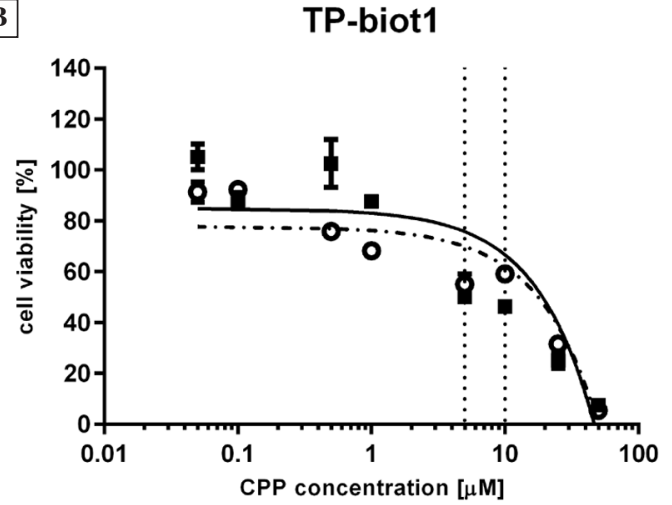

D

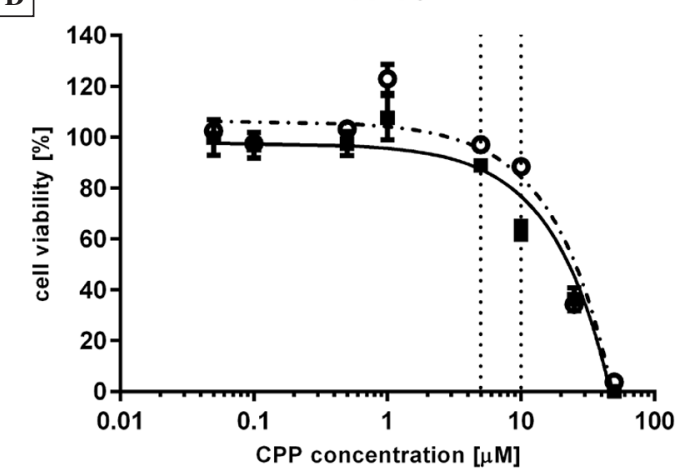

-๑- HT29

$\rightarrow$ HCT116

.. regression line for $\mathrm{HT} 29$

- regression line for HCT116

$\ldots$ cell viability levels at 5 and $10 \mu \mathrm{M}$ CPP concentration

Figure 1. Effects of transportan and its derivatives on the viability of HCT116 and HT29 cells. Cells were incubated with various concentrations of transportan (TP) and its derivates for $24 \mathrm{~h}$ and cell viability was assessed by MTT assay as described in Methods. Plots present mean \pm SD from 3 independent experiments. Circles and squares correspond to HT29 and HCT116 cells, respectively. X axis represents CPP concentration in logarithmic scale; for 5 and $10 \mu \mathrm{M}$ concentrations of CPPs vertical dotted lines were plotted. Y axis represents cell viability expressed as a percentage relative to the untreated control cells incubated without CPPs. Linear regression lines were plotted for both HT29 (dashed line) and HCT116 (solid line) cell lines. Lines' equations are not shown

comparatively small, but statistically significant increase in fluorescent signal for TP-biot13 was observed only at $4 \mu \mathrm{M}$ concentration in HCT116 cells (Figure 3A). No fluorescent signal was noticed when the combination of strept-FITC with sole TP or TP10 were used. The negative controls of cells treated only with strept-FITC or CPPs also showed no signal (data not shown).

\section{Endocytosis is not involved in the streptavidin transport by CPPS}

The possible involvement of endocytosis and other vesicle-based cellular trafficking pathways in streptavidin introduction into the studied CRC cells were blocked with the use of brefeldin A. Since TP-biot13 
Table 2. Lethal doses of the studied CPPs

\begin{tabular}{|l|c|c|c|c|c|c|}
\hline \multirow{2}{*}{ CRC cell line } & \multirow{2}{*}{ Lethal dose } & \multicolumn{5}{|c|}{ Cell penetrating peptides $[\boldsymbol{\mu M}]$} \\
\cline { 3 - 7 } & & TP & TP-biot1 & TP-biot13 & TP10 & TP10-biot1 \\
\hline HT29 & LD50 & 17.99 & 17.75 & 38.52 & 26.62 & 12.82 \\
\hline & LD90 & 36.54 & 43.35 & 80.65 & 43.81 & 39.97 \\
\hline HCT116 & LD50 & 24.19 & 19.15 & 31.13 & 22.82 & 16.87 \\
\hline & LD90 & 43.38 & 41.16 & 68.83 & 41.95 & 38.46 \\
\hline
\end{tabular}

LD50, LD90 - concentration of CPP that is sufficient to kill 50 or 90 percent of cells within 24 h. LD50 and LD90 concentration values were calculated using interpolation based on a regression line plotted in Figure 1. LD90 values were written in italics

A

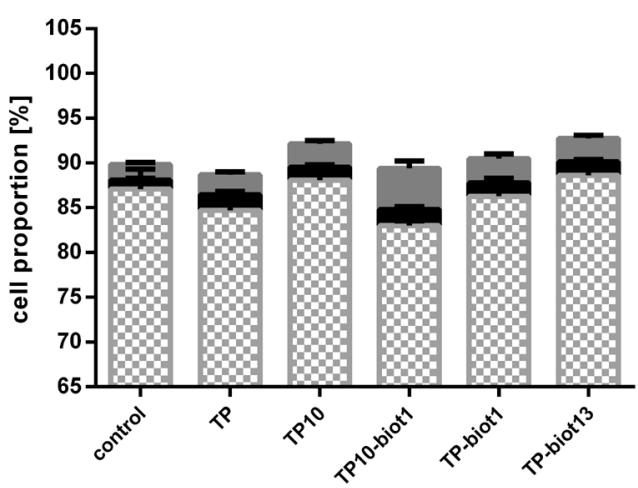

C

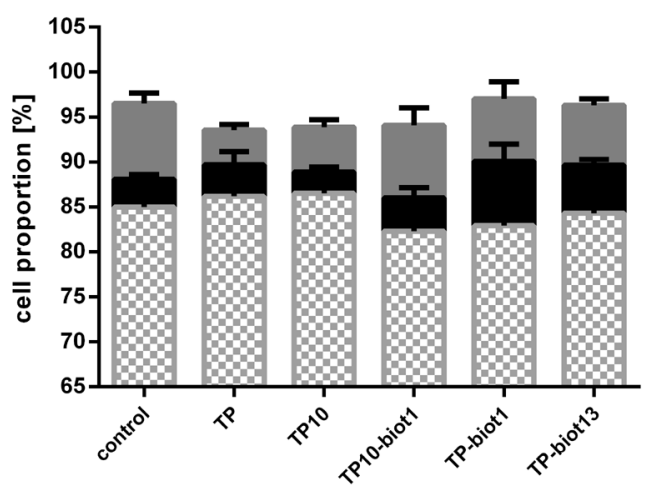

B

HT29 apoptotic assay $48 \mathrm{~h}$

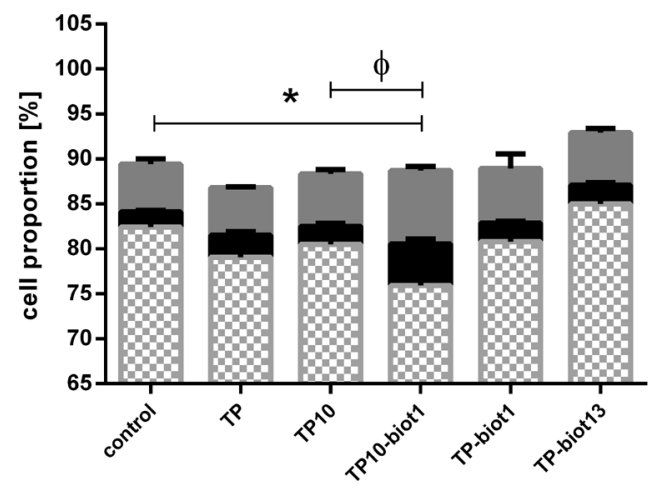

D

HCT116 apoptotic assay 48 h

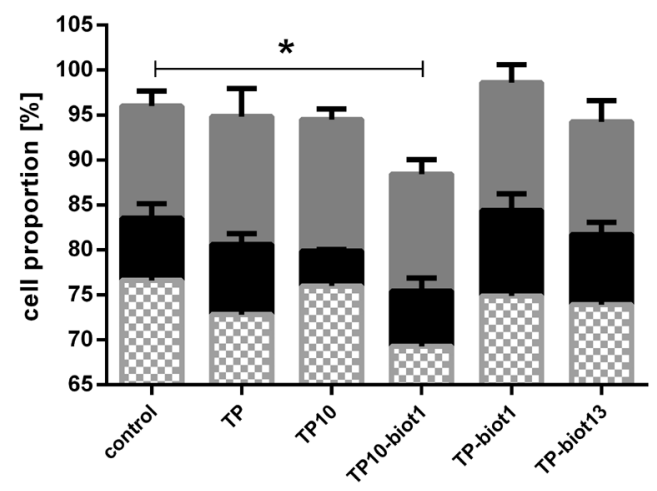

Figure 2. Apoptosis-inducing capability of transportan and its derivates in HT29 and HC116 cell lines. HT29 (A-B) and HCT116 (C-D) cells were incubated with transportan (TP) and its derivates at the concentration of $5 \mu \mathrm{M}$ for 24 or $48 \mathrm{~h}$. Apoptosis was assessed by Annexin V FITC Apoptosis Assay as described in Methods. Bars (mean \pm SD) represent: live cells (chequered pattern); late apoptotic cells (black); early apoptotic cells (dark grey). ${ }^{*}, \phi$ refer to statistically significant differences between viable cells of control sample or sample treated with TP10 vs. its biotinylated derivative, respectively $(\mathrm{p}<0.05 ;$ Kruskal-Wallis ANOVA test)

showed poor delivery rate (Figure 3), only on TP-biot1 and TP10-biot1 were studied. The intracellular transport of strept-FITC-CPP conjugate was not inhibited by brefeldin A treatment. Although the increased fluorescent signal for TP-biot 1 at $4 \mu \mathrm{M}$ concentration was lower after incubation with brefeldin A than without endocytosis inhibition (5-fold $v s$. 7-fold signal in HT29 and 3-fold vs. 4-fold signal in HCT116 cells) (Figures 3 and 4), it was significantly higher than in control cells. Moreover, the efficiency of transport across the plasma membrane was proportional to CPP concentration (Figure 4). Comparable efficien- 
$\mathbf{A}$

HT29 cells

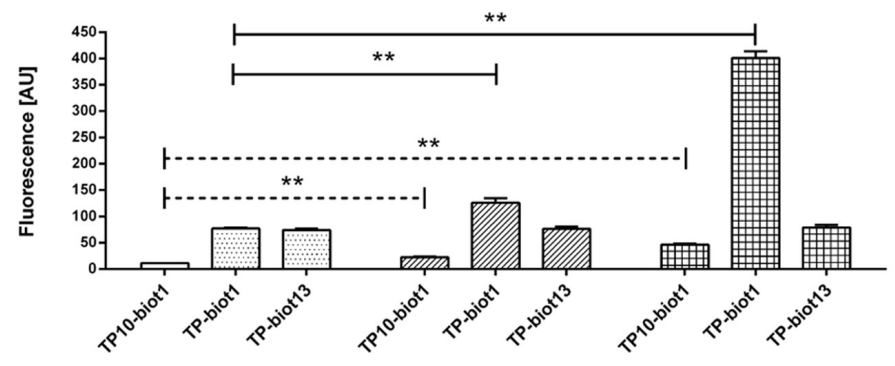

HCT116 cells

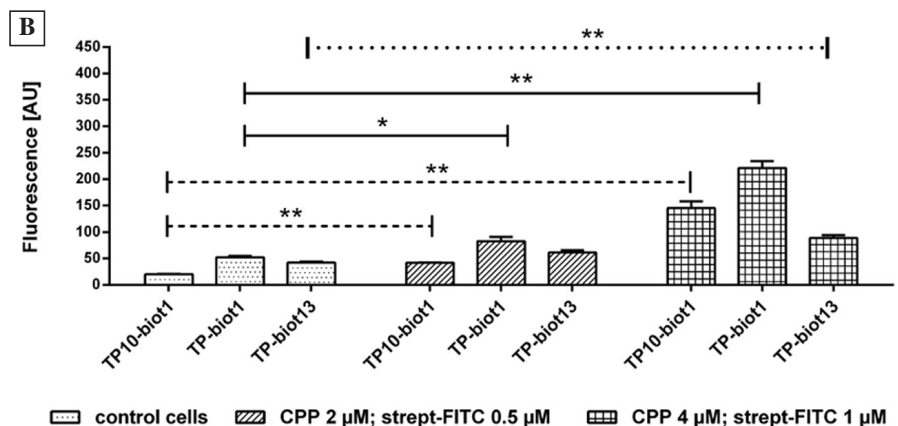

Figure 3. CPP-mediated streptavidin-FITC delivery to HT29 (A) and HCT116 (B) cells. Cells were incubated for $2 \mathrm{~h}$ without (dotted bars) or with CCP and streptavidin-FITC at the ratios of $2 / 0.5 \mu \mathrm{M}$ (hatched bars) or $4 / 1 \mu \mathrm{M}$, (crossed bars), respectively. Bars represent fluorescent values (mean $\pm \mathrm{SD}$ ) of three independent experiments. * ${ }^{*} *$ refer to significant differences between cells incubated with CPP-streptavidin-FITC and control cells ( $\mathrm{p}<0.05$ and $\mathrm{p}<0.01$, respectively; Mann-Whitney U test)
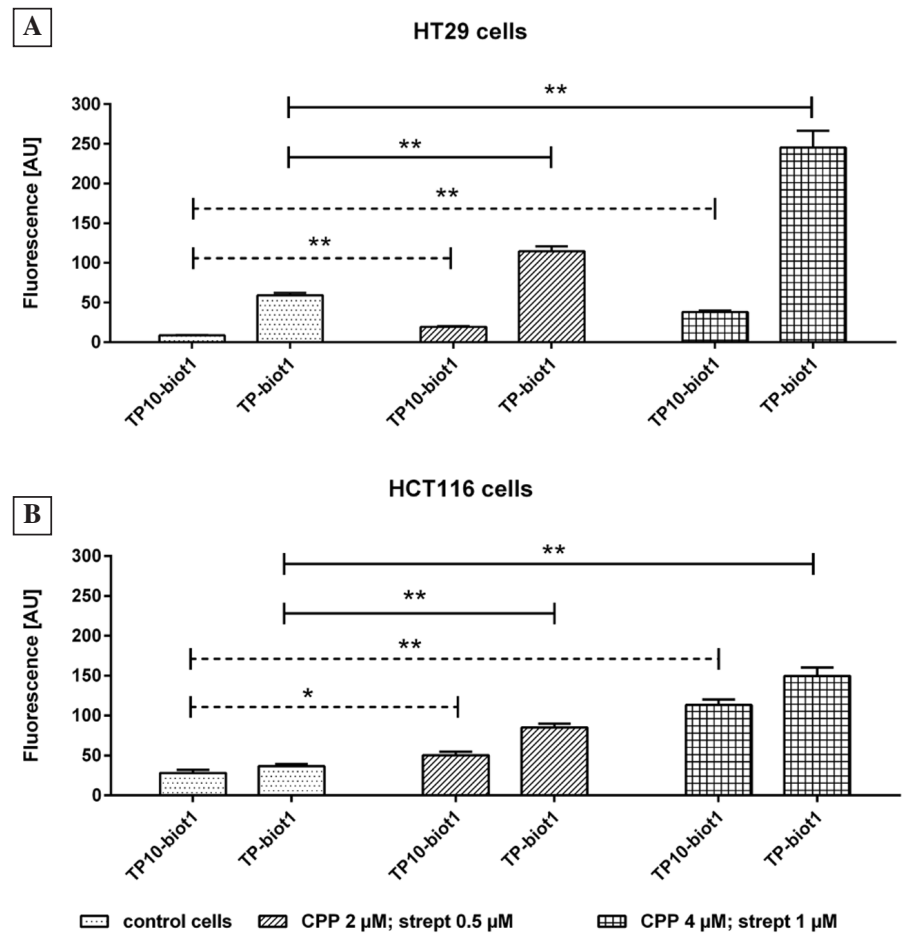

Figure 4. Influence of endocytosis inhibition on cargo introduction into HT29 (A) and HCT116 (B) cells. Cells were incubated with $10 \mu \mathrm{g} / \mathrm{mL}$ brefeldin A for $1 \mathrm{~h}$ before addition of streptavidin and CPPs as described in Methods. Bars represent fluorescent values (mean $\pm \mathrm{SD}$ ) of three independent experiments. * ${ }^{* *}$ refer to significant differences between cells incubated with CPP-streptavidin-FITC complex and control cells; $\mathrm{p}<0.05$ and $\mathrm{p}<0.01$, respectively; Mann-Whitney U test. Experiments did not include TP-biot13 due to its low efficiency of cargo introduction as shown in Figure 3 

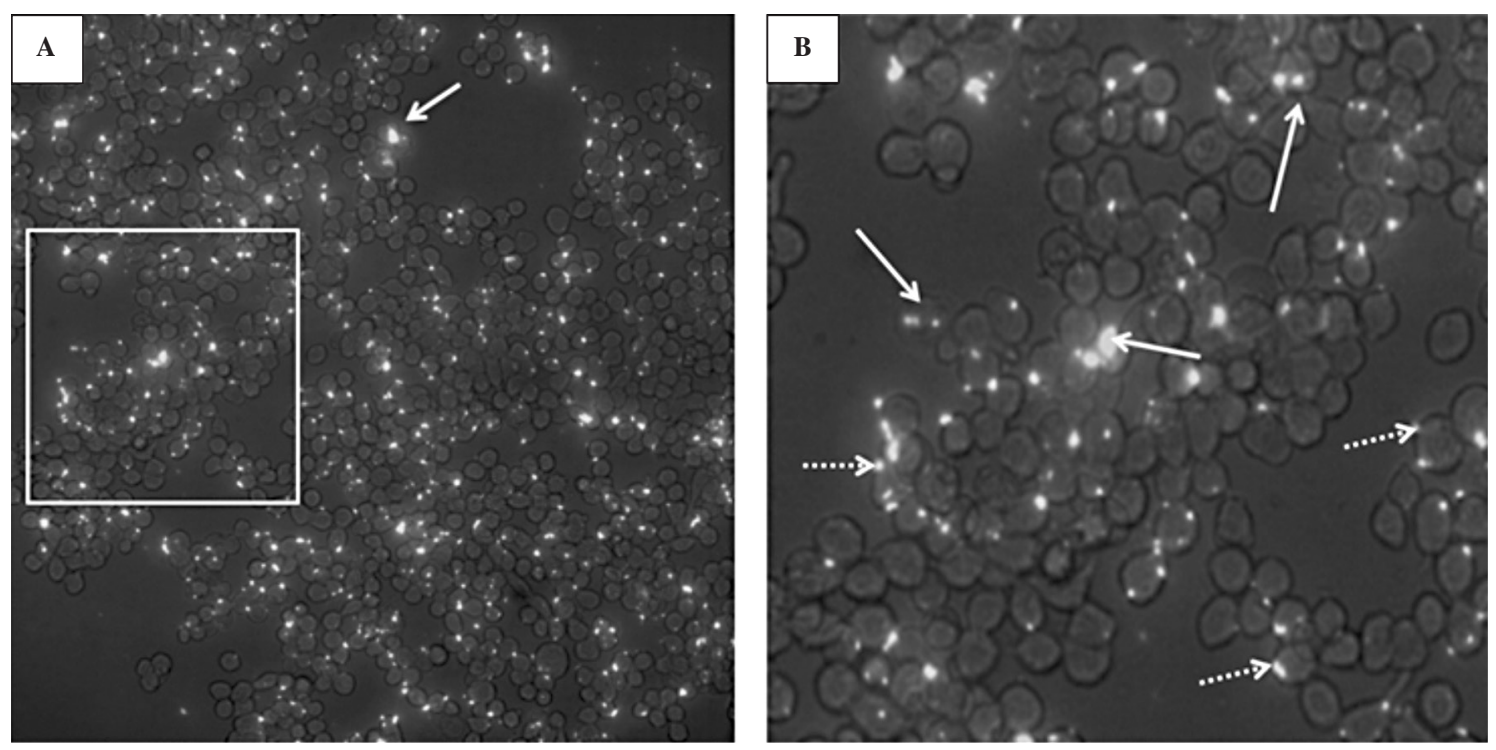

Figure 5. Streptavidin-FITC delivery into HT29 cells with the use of TP-biot1. Cells were incubated with $1 \mu \mathrm{M}$ TP-biot1 and $0,25 \mu \mathrm{M}$ strept-FITC for $1 \mathrm{~h}$. Fluorescence microscopy was performed as described in Methods. The streptavidin-FITC complexes bound to plasma membranes are pointed with dotted arrows, whereas solid arrows show streptavidin-FITC clumps in cytoplasm. Control cells incubated only with streptavidin-FITC did not show any fluorescent signal (not shown). Objective magnification: $\times 10(\mathbf{A})$ and $\times 20(\mathbf{B})$

cy of TP10-biot1 mediated transport of streptavidin complex with or without brefeldin A was observed (Figures 3 and 4). These results show that endocytosis was not involved in the mechanisms of large protein cargo delivery into CRC cell lines by TP-biot1 and TP10-biot1.

\section{Intracellular localization of streptavidin-FITC/ /TP-biot1 intracellular complex}

Based on the highest delivery rate of streptavidin conjugated with TP-biot1 into HT29 cells compared to control cells (Figure 3A), we performed the qualitative study of cellular location with the use of fluorescent microscopy. Since the concentrations of $\mathrm{CPPs} /$ strept-FITC used for quantitative studies showed very intense fluorescence signal (data not shown), we had to decrease concentration down to $1 / 0.25 \mu \mathrm{M}$ TP -biot1/strept-FITC and shorten the incubation time to $1 \mathrm{~h}$. The fluorescence clusters were deposited on the cytoplasmic side of the plasmalemma, as well as they were bound to intracellular membranes (Figure 5A, B).

\section{CPP-mediated siRNA delivery into cells}

The efficiency of siRNA delivery was checked by measurement of intracellular SASH1 mRNA levels in comparison to control cells with the use of qPCR technique (Figure 6). CRC cells were incubated with

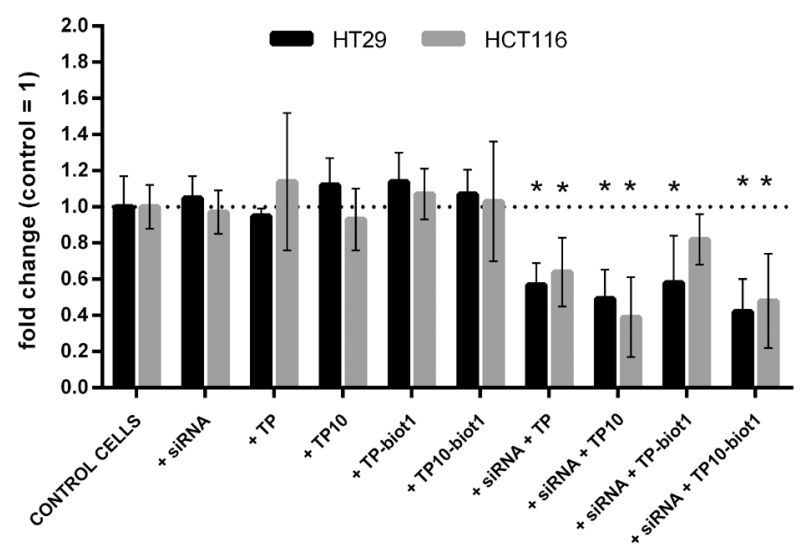

Figure 6. Efficiency of siRNA delivery into CRC cell lines with CPP assistance. HT29 and HCT116 cells were incubated for 12, 24 or $48 \mathrm{~h}$ with siRNA $(50 \mathrm{nM})$ and CPPs at the concentration of $2 \mu \mathrm{M}$. Total RNA isolation from all cells followed by reverse transcription was described in Methods. SASH1 mRNA levels were assessed by qPCR and normalized to GAPDH mRNA content in each sample, followed by calibration to control cells which were set to 1 . Bars represent mean \pm SD SASH1 expression values measured at all-time points $(12,24$ and $48 \mathrm{~h})$ in three replicates for each time-point. *significant differences between control and treated cells; $\mathrm{p}<0.05$ (Mann-Whitney U test)

siRNA for $S A S H 1$ mRNA at 10 or $50 \mathrm{nM}$ concentration in a presence of CPPs. Based on the results of the streptavidin delivery into the cells and due to shortage 
of available siRNA, we did not use TP-biot13 in this experiment. No differences were observed in mRNA expression ratio when $10 \mathrm{nM}$ siRNA was used (data not shown). Significant decrease of SASH1 mRNA content were observed when HT29 and HCT116 cells were preincubated with $50 \mathrm{nM}$ siRNA before CPPs were added (with one exception - TP-biot1 in HCT116 cells). Simultaneously, no significant changes in the SASH1 mRNA levels were observed in cells treated only with CPPs or siRNA (Figure 6).

\section{Discussion}

The ability to cross the cellular lipid bilayer and access the cell interior is still one of the major obstacles to overcome in order to progress current drug development. Therefore, various techniques have been developed in order to improve cellular uptake of bioactive agents [33]. CPPs are the promising factors which can improve the introduction of bioactive substances into tumor cells [18]. To date, the CPPs-mediated cargo delivery in in vitro conditions has been widely studied [9]; however, just few studies were performed on CRC-derived cell lines. E.g. the efficiency of cargo introduction by TAT into HT29 [34] and BR2 into HCT116 cells was reported [35]. Our study is the first focused on the effects of TP, TP10 and their biotinylated derivates on cell viability and large protein cargo delivery into early-staged HT29 and metastatic colorectal cancer HCT116 cells. Moreover, we established the concentration ranges of TP, TP10 and their biotinylated derivatives which affected cell viability and induced apoptosis. In model cancer cell lines, HeLa and CHO (hamster ovarian cancer) cells appeared to be more sensitive to TP (LD50 $=4$ and $10 \mu \mathrm{M}$, respectively) [36].

Interestingly, our observation of similar effects of TP and TP10 on cell viability and cell cycle progression is puzzling since TP was shown to strongly down-regulate GTPase activity followed by decreased cell viability, due to the presence of full-mastoparan sequence, whereas TP10 had no effect on this enzyme [8]. Our findings could be explained by the reported up -regulation of KRAS protein (protein with GTPase activity) in HT29 cells [37] and Ras-GTP-activating protein in HCT116 cells [38] which may overcome the GTPase inhibitory effect of TP. On the other hand, the observed higher cytotoxic effect of TP10-biot1 as compared to TP-10 during prolonged incubation (up to $48 \mathrm{~h}$ ) with HT29 and HCT116 cells might be caused by increased pore formation in plasma membrane and induction of apoptosis [39].

Despite of cytotoxic effect exerted at concentrations higher than $18 \mu \mathrm{M}$ for TP and $23 \mu \mathrm{M}$ for TP10, those CPPs are still one of the foremost studied agents due to their high delivery ratio at non-toxic concentrations [40]. The main goal for all CPPs in cancer cell studies is to deliver anticancer agents into cytoplasm/nucleus without causing damage to the cell membrane. Recently, siRNA [41], plasmid DNA [34], PNA [42] or PMO (Morpholino oligomers) [43] agents have been intensively studied in order to trigger specific cellular responses via up or down regulation of gene expression. Moreover, CPPs were used for the induction of direct cellular death by the introduction of doxorubicin [44] or anti-cancer drug paclitaxel [45] into the cancer cells. Intriguingly, Song and colleagues observed that TP10 and its analogs preferentially entered cancer cells rather than normal cells [18]. The phenomenon of the uptake selectivity toward cancer cells could make TP10 and its analogs potent CPPs for drug delivery to these cells. Recently, the effects of a fusion peptide that contained the TP-bound LXXLL-motif of the human SRC-1 nuclear receptor box 1 was investigated in vitro in breast cancer cells line. This peptide induced dose-dependently cell death of breast cancer cells and this effect was not influenced by estrogen receptor (ER) status. It reduced also the viability and proliferation of hormone-unresponsive breast cancer MDA-MB-231 cells [46].

All the mentioned cargoes were characterized by small molecular masses and were covalently bound to CPPs which modified the molecular conformation of CPPs by the formation of disulfide bridges. The specific feature of our study, as opposed to the other ones, was to introduce large protein into cancer cells by establishing non-covalent bonds with the studied CPPs (CPP-biotin-streptavidin complex) [47].

Despite of the effective streptavidin delivery with the use of TP-biot1 and TP10-biot1, inefficient insertion with the use of TP-biot13 was observed. We suggest that steric hindrance of the streptavidin-biotin complex can heavily affect delivery capability of this TP derivative. The salt bridge between Lys ${ }^{13}$ of TP (or Lys ${ }^{7}$ in TP10) and phospholipids of the synthetic bilayer may be the key to TP transport across the plasma membrane [18]. Therefore, if Lys ${ }^{13}$ in TP-biot13 is hidden in the active site of streptavidin, then the occurrence of TP-plasma membrane effect may be less possible, due to steric hindrance. Although such explanation requires experimental verification, the positive results obtained with the use of TP-biot1 and TP10-biot 1 can be a partial confirmation of this hypothesis.

Large protein delivery usually occurs by the way of endocytosis [25, 48]. CPP/cargo complexes reside then in endosomal vesicles and only a minor portion of them is able to escape these compartments, which 
decreases enormously the bioavailability of the transported substances [49]. Räägel et al. described the population of complexes-containing vesicles with neutral $\mathrm{pH}$ observed during intracellular trafficking. Induction of vesicles with non-acidic $\mathrm{pH}$ could be crucial for the escape of $\mathrm{CPP} /$ cargo complexes from endosomal compartment [50]. On the other hand, CPPs may utilize two or more trafficking pathways depending on the experimental conditions [51]. Our studies refer to these observations as streptavidin transport by biotinylated TP and TP10 into CRC cell lines was independent of the endocytosis because brefeldin A did not inhibit this process. Brefeldin A was used to block cellular vesicle traffic pathways as it indirectly inhibits protein transport from the endoplasmic reticulum to the Golgi apparatus by preventing formation of COPI-mediated transport vesicles [52]. Moreover, the process of transport across the plasma membrane was CPP-concentration dependent. On the other hand, the blockage of vesicular transport reduced the efficiency of delivery in the case of TP-biot1 (Figures 3 and 4). Thus, endocytosis was not the main trafficking pathway for large cargo delivery by TP molecules in the studied CRC cell lines, although a partial contribution to this process, especially in the case of TP-biot1 cannot be excluded. To our knowledge, the analysis of intracellular trafficking of TP-biot1-strept-FITC and TP10-biot1strept-FITC complexes with the use of brefeldin A was not performed earlier.

Our studies showed also that the introduced complexes of TP-biot1-strept-FITC in HT29 cells were bound to cytoplasmic side of plasmalemma or to intracellular membranes. This observation is in agreement with the reported location of other CPPs, such as TAT [53] or TP and its derivatives TP10 and TP14 [8].

We also checked if a small molecular mass cargo, siRNA, could be transported into CRC cells by analyzed CPPs. In theory, after successful delivery, siRNA should decrease the mRNA level of targeted gene, hence the comparison of $S A S H 1$ transcript level between control (no siRNA) and siRNA + CPP-treated cells should determine the efficiency of delivery. Since we noted the efficient decrease of intracellular $S A S H 1$ mRNA level by $S A S H 1$-specific siRNA, we expect that the use of TP and its derivatives for siRNA delivery into CRC cell lines could be a good alternative to other siRNA-delivery systems, due to lack of negative effect on cell viability of analyzed CPPs.

In summary, we have documented that TP, TP10 and their biotinylated derivatives can be used as efficient delivery vehicles of small and large cargoes into CRC cells.

\section{Acknowledgments}

The study was supported by the grant no. N N401 005338 of the Ministry of Science and Higher Education. We also thank G. Parfianowicz, Ph.D., A. Jozwik, Ph.D., K. Lisowska, Ph.D., and M. Stanislawowski, $\mathrm{Ph} . \mathrm{D}$. for excellent technical support.

\section{References}

1. Saar K, Lindgren M, Hansen M et al. Cell-penetrating peptides: a comparative membrane toxicity study. Anal Biochem. 2005;345:55-65.

2. Cardozo AK, Buchillier V, Mathieu M et al. Cell-permeable peptides induce dose- and length-dependent cytotoxic effects. Biochim Biophys Acta. 2007;1768:2222-2234.

3. Amantana A, Moulton HM, Cate ML et al. Pharmacokinetics, biodistribution, stability and toxicity of a cell-penetrating peptide-morpholino oligomer conjugate. Bioconjug Chem. 2007;18:1325-1331.

4. Moschos SA, Jones SW, Perry MM et al. Lung delivery studies using siRNA conjugated to TAT(48-60) and penetratin reveal peptide induced reduction in gene expression and induction of innate immunity. Bioconjug Chem. 2007;18:1450-1459.

5. Astriab-Fisher A, Sergueev D, Fisher M, Shaw BR, Juliano RL. Conjugates of antisense oligonucleotides with the Tat and antennapedia cell-penetrating peptides: effects on cellular uptake, binding to target sequences, and biologic actions. Pharm Res. 2002;19:744-754.

6. Begley R, Liron T, Baryza J, Mochly-Rosen D. Biodistribution of intracellularly acting peptides conjugated reversibly to Tat. Biochem Biophys Res Commun. 2004;318:949-954.

7. Futaki S, Suzuki T, Ohashi W et al. Arginine-rich peptides. An abundant source of membrane-permeable peptides having potential as carriers for intracellular protein delivery. $J$ Biol Chem. 2001;276:5836-5840.

8. Soomets U, Lindgren M, Gallet X et al. Deletion analogues of transportan. Biochim Biophys Acta. 2000;1467:165-176.

9. Ruczynski J, Wierzbicki PM, Kogut-Wierzbicka M, Mucha P, Siedlecka-Kroplewska K, Rekowski P. Cell-penetrating peptides as a promising tool for delivery of various molecules into the cells. Folia Histochem Cytobiol. 2014;52. doi: 10.5603/ FHC.a2014.0034.

10. Hallbrink M, Floren A, Elmquist A, Pooga M, Bartfai T, Langel U. Cargo delivery kinetics of cell-penetrating peptides. Biochim Biophys Acta. 2001;1515:101-109.

11. Gros E, Deshayes S, Morris MC et al. A non-covalent peptide-based strategy for protein and peptide nucleic acid transduction. Biochim Biophys Acta. 2006;1758:384-393.

12. Morris MC, Deshayes S, Heitz F, Divita G. Cell-penetrating peptides: from molecular mechanisms to therapeutics. Biol Cell. 2008;100:201-217.

13. Pooga M, Kut C, Kihlmark M et al. Cellular translocation of proteins by transportan. FASEB J. 2001;15:1451-1453.

14. Deshayes S, Morris MC, Divita G, Heitz F. Cell-penetrating peptides: tools for intracellular delivery of therapeutics. Cell Mol Life Sci. 2005;62:1839-1849.

15. Padari K, Saalik P, Hansen M et al. Cell transduction pathways of transportans. Bioconjug Chem. 2005;16:1399-1410.

16. Saalik P, Niinep A, Pae J et al. Penetration without cells: membrane translocation of cell-penetrating peptides in the model giant plasma membrane vesicles. J Control Release. 2011;153:117-125. 
17. Duchardt F, Fotin-Mleczek M, Schwarz H, Fischer R, Brock R. A comprehensive model for the cellular uptake of cationic cell-penetrating peptides. Traffic. 2007;8:848-866.

18. Fretz MM, Penning NA, Al-Taei S et al. Temperature-, concentration- and cholesterol-dependent translocation of L- and D-octa-arginine across the plasma and nuclear membrane of CD34+ leukaemia cells. Biochem J. 2007;403:335-342.

19. Jiao CY, Delaroche D, Burlina F, Alves ID, Chassaing G, Sagan S. Translocation and endocytosis for cell-penetrating peptide internalization. J Biol Chem. 2009;284:33957-33965.

20. Dunkin CM, Pokorny A, Almeida PF, Lee HS. Molecular dynamics studies of transportan 10 (tp10) interacting with a POPC lipid bilayer. J Phys Chem B. 2011;115:1188-1198.

21. Song J, Kai M, Zhang W et al. Cellular uptake of transportan 10 and its analogs in live cells: Selectivity and structure-activity relationship studies. Peptides. 2011;32:1934-1941.

22. Madani F, Lindberg S, Langel U, Futaki S, Graslund A. Mechanisms of cellular uptake of cell-penetrating peptides. J Biophys. 2011;2011:414729.

23. Emans N, Zimmermann S, Fischer R. Uptake of a fluorescent marker in plant cells is sensitive to brefeldin A and wortmannin. Plant Cell. 2002;14:71-86.

24. Frankel G, Gil S, Dougan G. Effect of deoxymannojirimycin and Brefeldin A on Yersinia pseudotuberculosis invasin eukaryotic cell interaction. Microb Pathog. 1995;19:421-427.

25. Veldhoen S, Laufer SD, Restle T. Recent developments in peptide-based nucleic acid delivery. Int J Mol Sci. 2008; 9:1276-1320.

26. Kocic I, Ruczynski J, Szczepanska R et al. Cell-penetrating peptides modulate the vascular action of phenylephrine. Pharmacol Rep. 2011;63:195-199.

27. Eudes F, Chugh A. Cell-penetrating peptides: From mammalian to plant cells. Plant Signal Behav. 2008;3:549-550.

28. Siedlecka-Kroplewska K, Szczerba A, Lipinska A, Slebioda T, Kmiec Z. 3-Fluoromethcathinone, a structural analog of mephedrone, inhibits growth and induces cell cycle arrest in HT22 mouse hippocampal cells. J Physiol Pharmacol. 2014;65:241-246.

29. Weber PC, Ohlendorf DH, Wendoloski JJ, Salemme FR. Structural origins of high-affinity biotin binding to streptavidin. Science. 1989;243:85-88.

30. Korber C, Horstmann H, Satzler K, Kuner T. Endocytic structures and synaptic vesicle recycling at a central synapse in awake rats. Traffic. 2012;13:1601-1611.

31. Ezzat K, Helmfors H, Tudoran O et al. Scavenger receptor-mediated uptake of cell-penetrating peptide nanocomplexes with oligonucleotides. FASEB J. 2012;26:1172-1180.

32. Wierzbicki PM, Klacz J, Rybarczyk A et al. Identification of a suitable qPCR reference gene in metastatic clear cell renal cell carcinoma. Tumour Biol. 2014. doi: 10.1007/s13277-014-2566-9.

33. El-Andaloussi S, Jarver P, Johansson HJ, Langel U. Cargo-dependent cytotoxicity and delivery efficacy of cell-penetrating peptides: a comparative study. Biochem J. 2007;407:285-292.

34. Saleh AF, Aojula H, Arthanari Y, Offerman S, Alkotaji M, Pluen A. Improved Tat-mediated plasmid DNA transfer by fusion to LK15 peptide. J Control Release. 2010;143:233-242.

35. Lim KJ, Sung BH, Shin JR et al. A cancer specific cell-penetrating peptide, BR2, for the efficient delivery of an scFv into cancer cells. PLoS One. 2013;8:e66084.

36. Jones SW, Christison R, Bundell K et al. Characterisation of cell-penetrating peptide-mediated peptide delivery. $\mathrm{Br} \mathrm{J}$ Pharmacol. 2005;145:1093-1102.
37. Kam Y, Rubinstein A, Nissan A, Halle D, Yavin E. Detection of endogenous K-ras mRNA in living cells at a single base resolution by a PNA molecular beacon. Mol Pharm. 2012;9:685-693.

38. Zhang H, Zhang S, He H, Zhao W, Chen J, Shao RG. GAP161 targets and downregulates G3BP to suppress cell growth and potentiate cisplaitin-mediated cytotoxicity to colon carcinoma HCT116 cells. Cancer Sci. 2012;103:1848-1856 .

39. Barany-Wallje E, Gaur J, Lundberg P, Langel U, Graslund A. Differential membrane perturbation caused by the cell penetrating peptide Tp10 depending on attached cargo. FEBS Lett. 2007;581:2389-2393.

40. Eggimann GA, Buschor S, Darbre T, Reymond JL. Convergent synthesis and cellular uptake of multivalent cell penetrating peptides derived from Tat, Antp, pVEC, TP10 and SAP. Org Biomol Chem. 2013;11:6717-6733.

41. Arukuusk P, Parnaste L, Oskolkov N et al. New generation of efficient peptide-based vectors, NickFects, for the delivery of nucleic acids. Biochim Biophys Acta. 2013;1828:1365-1373 .

42. Fisher L, Soomets U, Cortes Toro V et al. Cellular delivery of a double-stranded oligonucleotide NFkappaB decoy by hybridization to complementary PNA linked to a cell-penetrating peptide. Gene Ther. 2004;11:1264-1272.

43. Moulton HM. Cell-penetrating peptides enhance systemic delivery of antisense morpholino oligomers. Methods $\mathrm{Mol}$ Biol. 2012;867:407-414.

44. Nasrolahi Shirazi A, Tiwari R, Chhikara BS, Mandal D, Parang $\mathrm{K}$. Design and biological evaluation of cell-penetrating peptide-doxorubicin conjugates as prodrugs. Mol Pharm. 2013;10:488-499.

45. Jang YL, Yun UJ, Lee MS et al. Cell-penetrating peptide mimicking polymer-based combined delivery of paclitaxel and siRNA for enhanced tumor growth suppression. Int $J$ Pharm. 2012;434:488-493.

46. Tints K, Prink M, Neuman T, Palm K. LXXLL peptide converts transportan 10 to a potent inducer of apoptosis in breast cancer cells. Int J Mol Sci. 2014;15:5680-5698.

47. Juliano R, Alam MR, Dixit V, Kang H. Mechanisms and strategies for effective delivery of antisense and siRNA oligonucleotides. Nucleic Acids Res. 2008;36:4158-4171.

48. Heitz F, Morris MC, Divita G. Twenty years of cell-penetrating peptides: from molecular mechanisms to therapeutics. Br J Pharmacol. 2009;157:195-206.

49. Lehto T, Simonson OE, Mager I et al. A peptide-based vector for efficient gene transfer in vitro and in vivo. Mol Ther. 2011;19:1457-1467.

50. Raagel H, Saalik P, Hansen M, Langel U, Pooga M. CPP-protein constructs induce a population of non-acidic vesicles during trafficking through endo-lysosomal pathway.J Control Release. 2009;139:108-117.

51. Madani F, Abdo R, Lindberg S et al. Modeling the endosomal escape of cell-penetrating peptides using a transmembrane pH gradient. Biochim Biophys Acta. 2013;1828:1198$-1204$.

52. Nebenfuhr A, Ritzenthaler C, Robinson DG, Brefeldin A. Deciphering an enigmatic inhibitor of secretion. Plant Physiol. 2002;130:1102-1108.

53. Rinne J, Albarran B, Jylhava J et al. Internalization of novel non-viral vector TAT-streptavidin into human cells. BMC Biotechnol. 2007;7:1. 